anatomy and in his book on the hand, has made a very wide sweep of the subject.

In the first two pages, he rightly lays great stress on accuracy of observation and pillories artists who have made anatomical errors in their pictures. The frontispiece is Rembrandt's "Lesson in Anatomy" and the comment on page 4 , is "Nicolas Tulp is represented displaying the superficial flexor muscles of the fingers arising from the radial condyle of the humerus." After all, Rembrandt's work is an artistic masterpiece.

Turn to Fig. 99 of this book. The extensor tendon of the third digit is erroneously represented as splitting over the middle phalanx and its sole insertion appears to be the distal phalanx.

Or again Fig. 75. The ulnar artery and superficial palmar arch are erroneously portrayed as being lateral to the flexor tendons of the fourth and fifth digits. More important still, the lumbrical canals, instead of proceeding along the lumbrical tendons to the pre-axial sides of the digits, appear to end against the flexor tendons over towards the ulnar side of the phalanges.

On page 64 , there is tabulated the anatomical nomenclature of the carpal bones. A list is made of the morphological, the Lyserian, the accepted British (1919) - the year and bracket are mine-the B.N.A. and "other" classifications. At the present time, the new Birmingham revised terminology is used almost everywhere in Britain, ahd most textbooks have been printed in it. Why has this terminology been omitted and ignored?

There is in the book a certain amount of loose phraseology. On page I64 appears "In dense superficial fascia inflammatory products may be localised, but in lax superficial fascia they may spread. In this way a 'boil' upon the back of the neck may be expressed as a 'cellulitis' upon the front of the throat." Firstly, what is meant by this? Secondly is it true? We have opened many a boil on the fore-arm where the superficial fascia is lax. If a certain amount of latitude and liberty is taken with regard to known pathology and ascertainable facts, the theories which are advanced and which abound in the text and which make stimulating and extremely interesting reading must all be examined critically. The book is one to be read, thought about, and digested-not one to be swallowed whole.

\section{ILLUSTRATIONS OF BANDAGING AND FIRST AID}

By LoIs OAKes, S.R.N., D.N. E. \& S. Livingstone, London. 1942. Price 6s.

The fact that a second edition of this book has been called for within two years of its publication is proof enough of its value. It deals with a practical subject in a practical manner, by means of numerous and excellent illustrations. The publishers are to be thoroughly congratulated on the high quality of the paper and photographs in these difficult times, and especially on the moderate price for a book of 250 pages consisting mostly of illustrations.

There are few criticisms. The summary of the signs of fractures might perhaps becurtailed; is there any difference between "deformity" and "irregularity in alignment"? In the treatment of haemoptysis, advice to "turn the face to the affected side" is not altogether correct; it is immaterial which way the face is turned as it is merely to empty the upper air passages so that the patient is not choked by blood, and in any case it is often difficult even for

\section{Nasal Colds and Simusitis in Children}

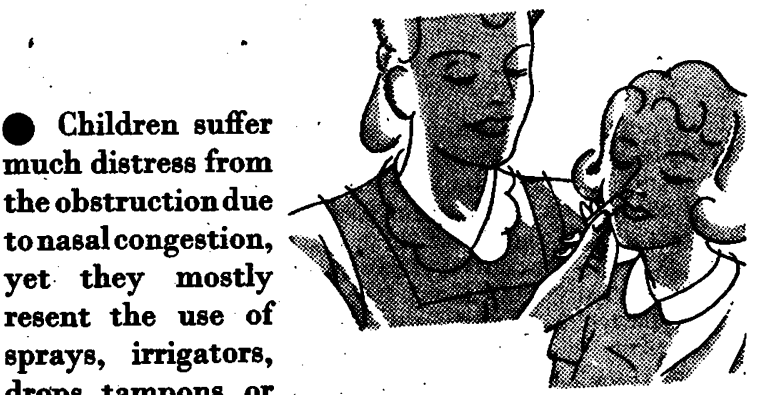
drops, tampons, or jellies designed for its relief.

KARSODRINE INHALER provides an admirable method of alleviating the condition. It is simplicity itself to use, and does not irritate the nasal passage or frighten the child. Even very young children quickly learn to use it and enjoy the process.

Since it promotes maximal drainage and aeration KARSODRINE INHALER minimizes the risk of complications such as paranasal sinusitis. Obtainable from all chemists $1 / 6 d$. including tax.

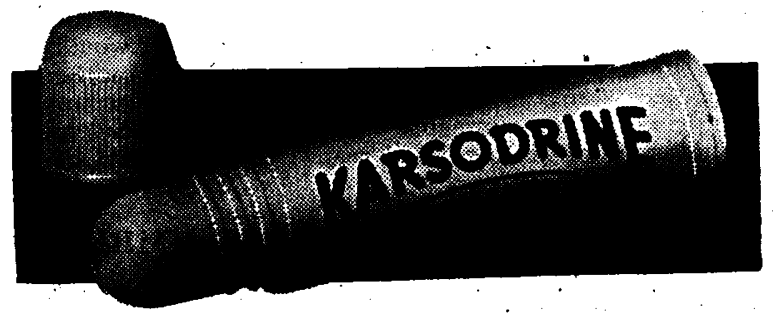

\section{R Each Karsodrine Inhaler Contains: \\ Amphetamaine $0.330 \mathrm{grm} . ;$ Gineole $0.093 \mathrm{grm} . ; \mathrm{Ol}$. Citronell. $0.026 \mathrm{grm}$.; Methyl Salicyl. $0.023 \mathrm{grm} . ;$ Ol. Cedri. 0.005 grm.; Menthol 0.049}

\section{Free Clinical Samples}

Free samples of the Karsodrine Inhaler for Surgery use will gladly be sent to any member of the medical profession. Please address your request to: Karsodrine Clinical Department, E. Griffiths Hughes Ltd., Adelphi, Salford 3; Manchester.

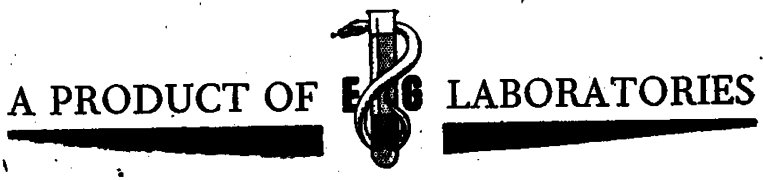


the physician to locate the side of the pulmonary lesion.

These are small points, of course, not actually dealing with the main theme of bandaging, on which subject this book might easily be the standard reference for all classes of worker, not least medical students and doctors.

\section{HANDBOOK OF HYGIENE}

By Joseph W. Bigger, M.D., Sc.D. Second Edition. Pp. xii, 4I4. I 8 illustrations, including I plate. Baillière, Tindall \& Cox. I94 I Price I2s. 6d.

The call for a second edition, within four years, of Professor Bigger's Handbook of Hygiene is, in itself, an indication of.the value of this work. A number of changes, as the author shows in his Preface, have been made; and all of them are welcome.

It is to be noted, that in the new edition the section on chemical warfare, very rightly, has been omitted. A useful, and indeed interesting, new chapter on the relations between the practitioner and the Public Health Service, written by Dr. C. J. McSweeney, has been added. Here, the medical man in general practice will find succinctly put an outline of the activities of his administrative colleague. The duties of the Health Department in the field covering the care of the mentally subnormal child, facilities for the education nowadays provided for blind, deaf and stammering children, the care of school children, the care of the undernourished child, sufferers from rheumatism and, in fact, the varied and multitudinous activities of the Public Health Service are shortly touched on-a valuable chapter.

As an offset to this, the space devoted to vital statistics is meagre, and the amount of information to be obtained from it is insufficient for students or for reference by practitioners. On the other hand, the book seems somewhat over-balanced by the space devoted to communicable diseases. It would seem that Professor Bigger, having embarked on the subject, found himself getting more and more committed to an immense subject. Every reader, however, of his book will realise the difficulties of making a Public Health appreciation of diseases as diverse as diphtheria, dengue, Delhi Boil or dysentery, to mention a few. It is, however, somewhat sad-making to read that contacts of German measles "should be quarantined for twenty-one days.". Such a practice would not do for the Forces in these times!! Nor does it seem to be sound policy to describe methods of treatment in a Handbook of Hygiene. Here, for instance, we may learn how to treat a case of scabies.

Mention is made of the complications arising from rapid transport by plane of passengers and potentially infective or infected Aedes aegypti from areas in Africa, particularly where yellow fever has existed in latent form. An epitome of the regulations imposed on passengers coming from such areas would haverbeen valuable.

The note on the control of Venereal Diseases, whilst being informative, is, as can only be expected, not particularly helpful. As the author says, the problem bristles with difficulties, medical, social and legal.

Diseases of uncertain origin, such as diabetes and cancer, are discussed following a chapter on disinfection.

Chapters on The Science of Hygiene, as affecting water supplies, food, ventilation and disposal of waste follow conventional lines. Many of the illustrations are old friends.

There follow short chapters on Occupational - Hygiene, Maternity and Child Welfare and an extremely well thought out Treatise on Personal Hygiene. It is worrying, however, to read in a work on Hygiene and Public Health, and particularly in days of a paper shortage, details of how blood pressure readings should be obtained.

In summary, then, this little manual of less than 400 pages is a mine of information. It is written in an attractive style, and it is, in the result, not only easy, but a pleasure, to read. If every student, before taking his Final in Medicine, could find time and opportunity to give a short and concentrated study to a large part of this book, he would find his examiners much more sympathetic towards his efforts to satisfy them. And, if he remembered only a small proportion of what he had read, he would be a well-informed candidate.

\section{SPECIAL NUMBERS OF THE JOURNAL}

Special numbers have been published from time to time, each dealing comprehensively with a particular branch of medicine or surgery. These special numbers are as follows, and copies, price 2s. each, post free, may be obtained from the Fellowship of Medicine, I Wimpole Street, London, W.r. A list of contents of any individual number will be sent on application.

\begin{tabular}{|c|c|c|}
\hline OBStETRICS & (August, I933) & Cerebral Tumours \\
\hline OPHTHALMOLOGY & (August, 1934) & (February, I940) \\
\hline NeUrology & (April, I935) & *War Wounds of the Chest \\
\hline UROLOGY & (November, 1935) & *War Wounds of the Abdomen \\
\hline CARDIOLOGY & (April, I936) & *War Wounds of the Limbs \\
\hline Proctology & (August, 1936) & *WaR Wounds of the Eye and ORBI T (June, I949) \\
\hline NEPHRITIS & (February, 1937) & *War Wounds of the Head and Face (July, I940) \\
\hline RHEUMATISM & (September, 1937) & (January/February, I94I) \\
\hline ORTHOPÆDICS & (October, 1937) & Vitamins D AND “Newer" Vitamins (March, I94I) \\
\hline Tropical Diseases & (November, 1938 ) & $\begin{array}{l}\text { Vitamin A and Summary } \\
\text { MEdicine in the U.S.S.R. }\end{array}$ \\
\hline
\end{tabular}

